\title{
Numerical simulation of air flow in short metro ventilation shafts caused by a piston effect
}

\author{
Nicolae Ilias ${ }^{1 *}$, Omar Lanchava ${ }^{2,3}$, and Giorgi Nozadze $^{2}$ \\ ${ }^{1}$ University of Petrosani, Department of mechanical engineering, 20 Universitaria, Petrosani, \\ Romania \\ ${ }^{2} \mathrm{G}$. Tsulukidze Mining institute, Underground structures construction \\ and mining technologies center, 7 Mindeli, Tbilisi, Georgia \\ ${ }^{3}$ Georgian Technical University, Department of occupational safety and emergency management, 77 \\ Kostava, Tbilisi, Georgia
}

\begin{abstract}
Protecting the infrastructure of the metro from unauthorized actions with the help of ventilation openings of the systems is one of the main security problems of this type of transport. This article discusses the problem of the dynamics of distribution of the mass flow rate of ventilation air in a two-component system "tunnel - vertical ventilation shaft", due to the piston effect of a moving train. The dependence of the mass flow rate of ventilation air passing in both directions in short ventilation shafts (up to $10 \mathrm{~m}$ ), on the speed, location of the rolling stock and cross-sectional area of the ventilation shaft is investigated. It is shown, that at speeds of 10-20 $\mathrm{m} / \mathrm{s}$ of rolling stock and sections of the ventilation shaft of more than 4 $\mathrm{m} 2$, the mass flow rate of air passing through the ventilation shaft must be taken into account with the mass flow rate of ventilation air in the transport tunnel for assessing the safety of the harmful aerosols. These processes can have a significant impact on the air quality of the underground infrastructure of the metro.
\end{abstract}

\section{Introduction}

Under the conditions of modern technological development, the most important task of the metro is to provide security measures in the context of growing environmental and terrorist threats. Through the vertical ventilation shafts, depending on the location of the trains, the effect of the piston caused by the movement of trains changes the direction of the air flow several times (at least 20 times per hour), which in certain cases can be considered as the possibility of distribution of uncontrolled air into the underground space. Therefore, there is the necessity to establish patterns of distribution air flows in the underground space using the methods of mathematical modeling. The modeling should be carried out taking into account the turbulence and inertia of the ventilation flow, as well as taking into account the different location of the train in the tunnels, the nature of its movement at different values of the cross section of the vertical shafts.

\footnotetext{
Corresponding author: iliasnic@yahoo.com
} 
As a rule, the aerodynamics of the piston effect is a complex multi-parameter problem. Consequently, the reliable determination of the aerodynamic resistance coefficient, which characterizes aerodynamics, meets with fundamental difficulties. To overcome the noted difficulties, in the present work it is assumed that similar processes take place in similar systems, and therefore using numerical and analytical methods, depending on the location of the train in the tunnel, the resistance coefficients are estimated, which can be interpreted as the first correlation. As it is known, the indicated coefficients are widely used in the traditional practice of aeromechanics.

In modern scientific literature, many scientific papers have been devoted to the study the air flow caused by the piston effect of a moving train. In most works, the piston effect is considered as a positive factor in improving air exchange in the underground space. In work [1] the results of the study of air quality in underground structures of twenty countries of the world are considered.

The issue of the spread of uncontrolled air flow through the ventilation shafts, as we know, was not considered in the works of other authors. In the papers [2-4] deals theoretical analysis of the piston effect and results of numerical modelling in subway tunnels. In the papers $[5,6]$ tables and graphs of changes in air flows generated by the piston effect are presented depending on the speed of the train and the degree of fill rate of the tunnel. In the paper [7] it is noted that the piston effect is characterized by two phases: non-stationary and stationary. The article also presents the method of mathematical modeling of the piston effect and illustrates the choice of the size of the simulation cells. The paper [8] focuses on the challenge of the air flow estimation by means of measurements and numeric analyses.

In papers [9-11], the piston effect created by traffic has been considered and it is noted that this effect pushes air from the tunnel to the platform and the concentration of solid particles in the air increases as trains approach the platform. In work [12], problems of supplying fresh air to a metro station were considered, taking into account unorganized inflows caused by the influence of the piston effect, as well as temperature differences caused by the air conditioning. In the work [13], the effect of the piston is considered as an opportunity to save energy spent on airing the underground space.

In the paper [14], as well as in [11] noted that particle generation in underground space occurs by mechanical wear at the brake-wheel and wheel-rail interfaces, where magnetic metallic flakes and splinters are released and undergo progressive atmospheric oxidation.

\section{Numerical Simulation Technique}

Below are presented the initial and boundary conditions for solving the task by means of the commercial software Pyrosim 2016:

- Geometric parameters tunnel of metro are: length $-L_{0}=800 \mathrm{~m}$; Area of cross section $S_{0}=20 \mathrm{~m}^{2}$; Perimeter $-P_{0}=18 \mathrm{~m}$, Ventilation shaft is located in the central part of the transport tunnel, which is separated from the portal $-L_{c}=L_{0} / 2$; The shaft cross section is variable and takes values $-S_{c}=1,4,9,16 \mathrm{~m}^{2}$, and the vertical height of the shaft $h_{c}=10 \mathrm{~m}$ from the tunnel ceiling;

- On the left portal of the tunnel there are the different meanings of excessive dynamic pressure $\Delta P_{k}=10,30,50 \mathrm{~Pa}$, while on the right portal are normal conditions - it means, that static pressure component does not change on the both portals;

- The location of the train in the tunnel counted off from the left portal and takes value $X_{t}=202,302,351,402,502,602 \mathrm{~m}$. Train length $-L_{t}=80 \mathrm{~m}$, cross section of the train $-\mathrm{S}_{\mathrm{t}}=9 \mathrm{~m}^{2}$, tunnel fill factor $-k=S_{t} / S_{0}=0.45$;

- The solution of the proposed task is to define the air flow mass ratio in the tunnel characteristic cross sections, which location are in distance from the left portal $-X_{c}=0$, 
$395,405,800 \mathrm{~m}$. Same time, the variable values of air mass exchanges for the central ventilation shaft in horizons are determined, with vertical distance $Z_{c}=6 \mathrm{~m}, 16 \mathrm{~m}$ from the tunnel bottom. The realization of the initial and boundary conditions of the task in the software is presented in Figures 1-2.
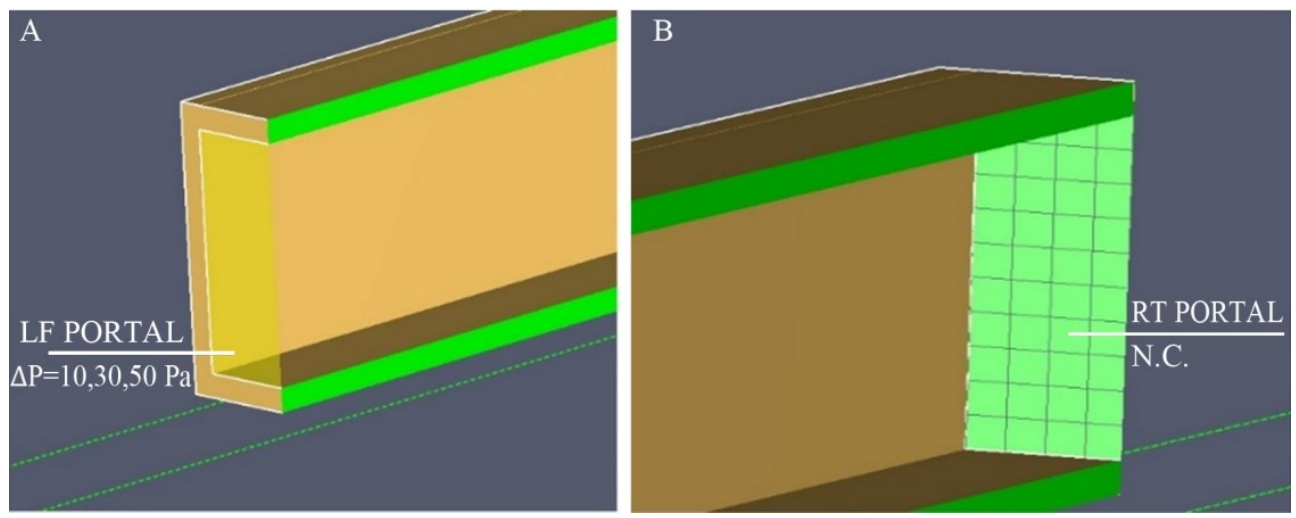

Fig. 1. (A) Boundary conditions at the left portal of transport tunnel are: $\Delta \mathrm{P}=10,30,50 \mathrm{~Pa}$ (B) Boundary condition at the right portal of transport tunnel are normal and Finite volume cell dimentions are $0.5 \times 0.5 \times 0.5 \mathrm{~m}$

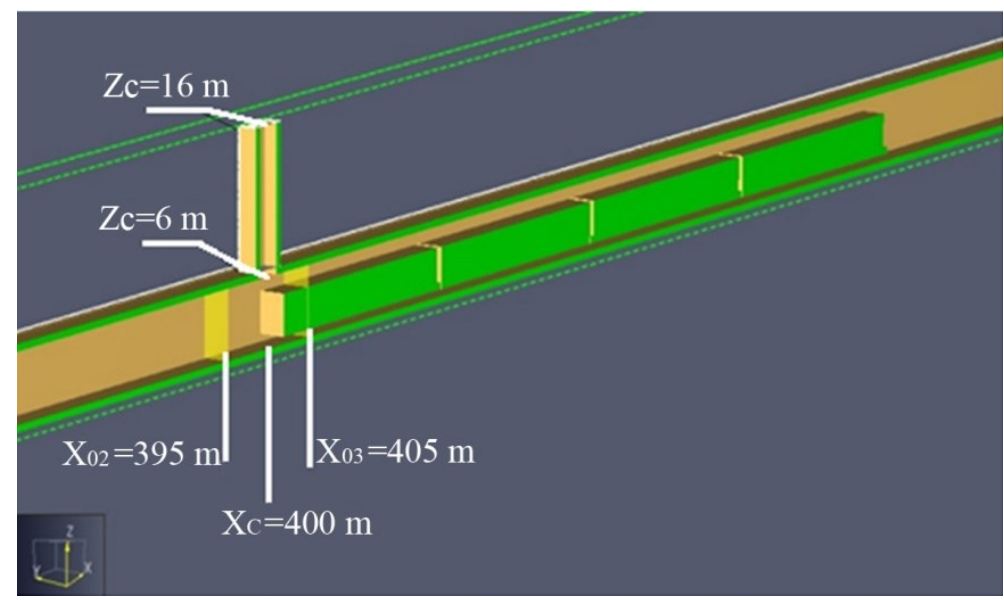

Fig. 2. Air mass rate detectors location in tunnel near of ventilation shaft: $395 \mathrm{~m}, 400 \mathrm{~m}, 405 \mathrm{~m}$ from left portal and $6,16 \mathrm{~m}$ from the bottom of tunnel

The train movement velocity diagram is represented on the Fig. 3 for the two operating speed from the practice of Tbilisi metro exploitation. They are: $V_{1}=10 \mathrm{~m} / \mathrm{s}, V_{2}=20 \mathrm{~m} / \mathrm{s}$. 


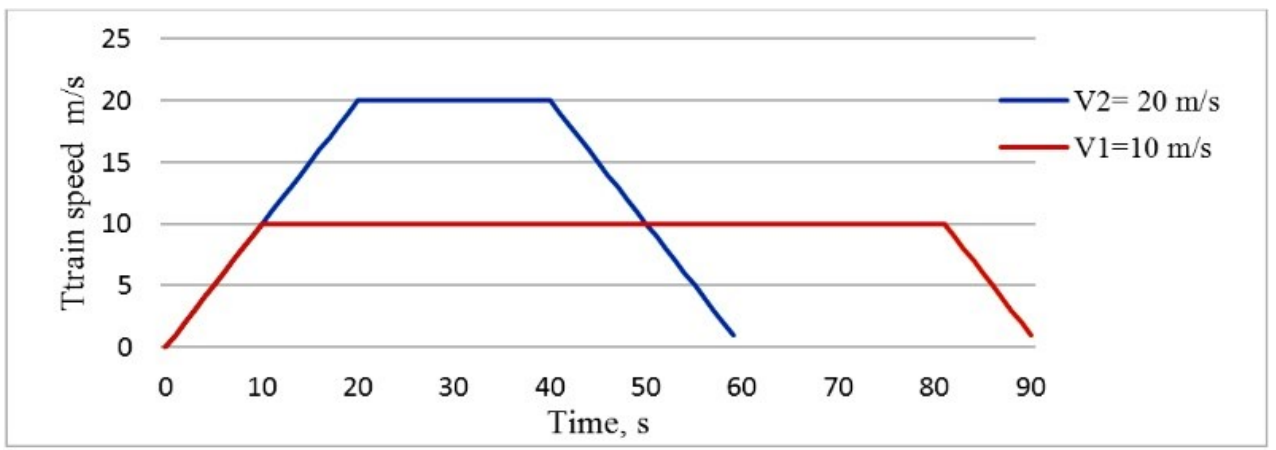

Fig. 3. Standard diagrams of train movement in the subway transport tunnel

\section{Results and discussion}

The results of modeling the reverse problem are presented as graphs on the Fig 4.

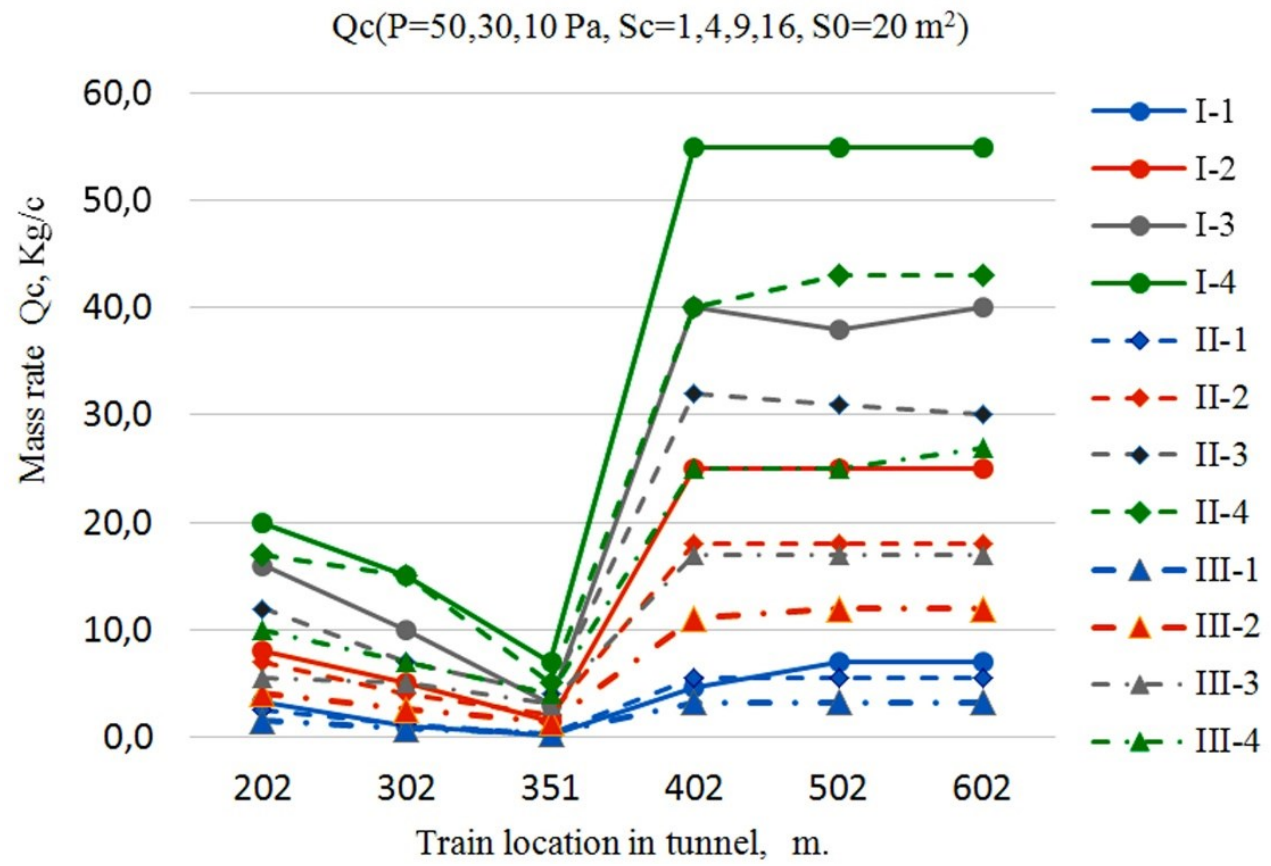

Fig. 4. Dependence of air mass rate in the ventilation shaft based on the location of the rolling stock in the transport tunnel for the boundary conditions: I- $50 \mathrm{~Pa}$, II-30 Pa, III -10 Pa and the shaft cross section areas: $1-S_{c}=1 \mathrm{~m}^{2} ; \mathbf{2}-S_{c}=4 \mathrm{~m}^{2} ; \mathbf{3}-S_{c}=9 \mathrm{~m}^{2} ; \mathbf{4}-S_{c}=16 \mathrm{~m}^{2}$

The reversibility of the problem lies in the fact that the stream of air of varying intensity moves through tunnel and blows a stationary train. Consequently, the tunnel in these tasks is similar to the aerodynamic tube, in which studies are carried out on fixed models of transport.

For the practical use of received results of numerical modeling by means of Basic Law of parallel networks have been calculated values of aerodynamic resistance coefficients $(\alpha)$ for investigated tunnels (vertical ventilation shaft and tunnel without and with train) by 
results of modeling. Consequently, in presented paper have been calculated mass rate of air flows investigated by numerical modeling for the listed sites. Basic Law air flows in the parallel networks for our task will be takes followed form

$$
R_{0} Q_{0}^{2}=R_{1} Q_{1}^{2}=R_{c} Q_{c}^{2}
$$

Where $R_{0}, R_{1}, R_{c}$ is aerodynamic resistance of the listed sites of tunnel, N.s ${ }^{2} / \mathrm{m}^{8}$;

$Q_{0}, Q_{1}, Q_{c}$ - mass part of the airflow, calculated in the cross sections of the listed sites, $\mathrm{kg} / \mathrm{s}$.

Considering that

$$
\Delta P_{k}=\mathrm{R}_{0} \mathrm{Q}_{0}^{2}, R_{1}=\frac{R_{0} Q_{0}^{2}}{Q_{1}^{2}}=\frac{\Delta \mathrm{Pk}}{Q_{1}^{2}}, R_{c}=\frac{R_{0} Q_{0}^{2}}{Q_{c}^{2}}=\frac{\Delta P_{k}}{Q_{c}^{2}} \text { and } R_{i}=\frac{L_{i} P_{i} \propto_{i}}{S_{i}^{3}}
$$

Where $\propto_{i}$ - is the aerodynamic resist ratio of the $\mathrm{i}^{\text {th }}$ section of the tunnel, N.s ${ }^{2} / \mathrm{m}^{4} ; \mathrm{L}_{\mathrm{i}-}$ the length of the $i^{\text {th }}$ section of the tunnel, $m ; P_{i}$ - the perimeter of the $i^{\text {th }}$ section of the tunnel, $m$; $\mathrm{S}_{\mathrm{i}}$ - the area of the $\mathrm{i}^{\text {th }}$ section of the tunnel, $\mathrm{m}^{2}$.

For the calculation of the aerodynamic resist ratio of the mentioned sections of tunnel were used formulas

$$
\propto_{0}=\frac{2 \Delta P_{k} S_{0}^{3}}{Q_{1}^{2} P_{0} L_{0}}, \propto_{1}=\frac{\Delta P_{k} S_{1}^{3}}{Q_{1}^{2} P_{1} L_{1}}, \propto_{c}=\frac{\Delta P_{k} S_{c}^{3}}{Q_{1}^{2} P_{c} L_{c}}
$$

Where $\propto_{0}$ is aerodynamic resist ratio of tunnel part without train, N.s ${ }^{2} / \mathrm{m}^{4} ; \propto_{1}$ aerodynamic resist ratio of tunnel part with train, $\mathrm{N} . \mathrm{s}^{2} / \mathrm{m}^{4}$ and $\propto_{c}$ - aerodynamic resist ratio of ventilation shaft, $\mathrm{N} . \mathrm{s}^{2} / \mathrm{m}^{4}$. For the calculation by formulas (3) there are an additional initial dates $-S_{t}=\left(1-k S_{0}\right)=11 \mathrm{~m}^{2}, L_{t}=80 \mathrm{~m}, P_{t}=P_{0}+P_{1}=20+12=32 \mathrm{~m}^{2}, S_{c}=1,4$, 9, $16 \mathrm{~m}^{2}, P_{c}=4,8,12,16 \mathrm{~m}, L_{c}=10 \mathrm{~m}$.

Below on the Fig. 5 are presented graphs of numerical calculation of aerodynamic resist ratio.

Taking into account the nonstationarity of the piston effect, by the phases of acceleration and decceleration of the moving trains in the first correlation can be considered the duration of the non-stationary phase of the movement of the air flow. Depending on the results of the numerical modeling on the speed of movement in the subway transport tunnel (see Figure 3), it is possible to determine the duration of the process of suction of atmospheric air into the transport tunnel through the ventilation shaft

$$
T_{c}=\frac{L_{0}-L_{t}}{V_{\max }}-\frac{V_{\max }}{2 a}
$$

Formula (4) also provides for the fact that there is no practical process of suction atmospheric air into the transport tunnel through the ventilation shaft when the train closes perimeter of shafts and because of this, the drag coefficient seems to take values close to infinity. The duration of aerodynamic processes, depending on the presented two working speeds $\left(\mathrm{V}_{1}=10 \mathrm{~m} / \mathrm{s}, \mathrm{V}_{2}=20 \mathrm{~m} / \mathrm{s}\right)$ and acceleration $a=1.0 \mathrm{~m} / \mathrm{s}^{2}$, calculated by the formula (4), gives the following time interval of $26 \mathrm{~s}<T_{c}<67 \mathrm{~s}$. 


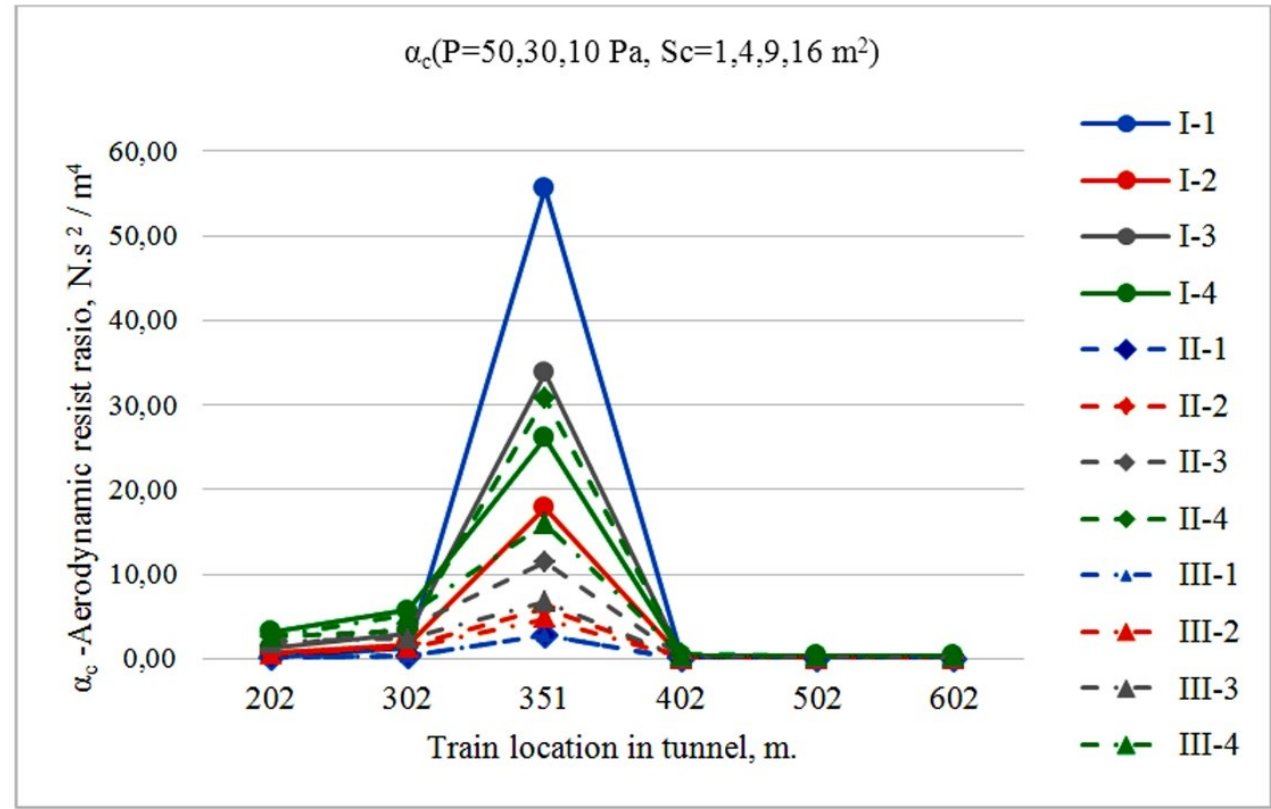

Fig. 5. Dependence of $\alpha_{c}$ - aerodynamic resist ratio in the ventilation shaft based on the location of the rolling stock in the transport tunnel for the boundary conditions: I- $50 \mathrm{~Pa}$, II-30 Pa, III -10 Pa and the shaft cross section areas: $\mathbf{1}-S_{c}=1 \mathrm{~m}^{2} ; \mathbf{2}-S_{c}=4 \mathrm{~m}^{2} ; \mathbf{3}-S_{c}=9 \mathrm{~m}^{2} ; \mathbf{4}-S_{c}=16 \mathrm{~m}^{2}$

The software for Numeric modeling use the finite volume method, where discrete volume units $0.5 \times 0.5 \times 0.5 \mathrm{~m}$ was selected by the recommendations of the Programmers, developed this software.

Validation of numerical modeling in the research process has been checked by the storage law of mass rate for the parallel networks. In the given task, mass rate detektors were located in the cross sections corresponding to coordinates $X=395 \mathrm{~m}, X=405,(X=$ $400 \mathrm{~m}, \mathrm{Z}=6 \mathrm{~m})$.

$$
Q_{X=395}=Q_{X=400}+Q_{X=405}
$$

Maximum relative error in the study process was $12.1 \%$.

$$
\Delta_{\max }=\frac{\mathrm{Q} 395-(\mathrm{Q} 400+\mathrm{Q} 405)}{\mathrm{Q} 395} * 100 \%=12,1 \%
$$

Based on numerical modeling of the presented task, we can determine the minimum depression and the amount of the volume of suction of atmospheric air depending on the length of the metro tunnel and the location of the train. In the presented task there are evidence to neutralize the flow caused by the piston effect of moving train.

The mass of the of suction of atmospheric air by the piston effect caused by the train movement in the transport tunnel can be calculated using the formula

$$
Q=\frac{Q_{C} T_{C}}{2}
$$




\section{Conclusions}

As part of the proposed work, the validation of numerical method was carried out using the example of the law of conservation of air mass for parallel networks. The accuracy of the results is approximately $12.1 \%$.

Based on numerical modeling, it was established that due to the influence of the piston effect, an uncontrolled mass of air can flow into the underground space, the flow rate of which depends on the velocity and location of the train in the tunnel, as well as on the cross section area of the shaft. According to the last indicator, the marked consumption has a clearly defined minimum and its effect on the aerodynamics of the underground space should be taken into account if the shaft cross section area is more than $4 \mathrm{~m}^{2}$.

Aerodynamic resistance coefficient for the vertical shaft as well as for the parts of tunnel with and without train can be determined by geometric data of the ventilation shaft and the location of the moving train in the transport tunnel taking into account the presented results.

\section{References}

1. B. Xu, J. Hao, Environment International 107, 33-46 (2017)

2. O. Lanchava, N. Ilias, G. Nozadze, S. Radu, R. Moraru, Z. Khokerashvili, N. Arudashvili, Environmental Engineering and Management Journal 18(4), 865-872 (2019)

3. O. Lanchava, G. Nozadze, Bulletin of the Georgian National Academy of Sciences 13(1), 38-44 (2019)

4. O. Lanchava, G. Nozadze, Proceedings of the The 10th International Multidisciplinary Symposium "Engineering Computational Technology 2018 - ECT 2018" (2018)

5. O. Lanchava, G. Nozadze, Z. Khokerashvili, N. Arudashvili, Mining Journal 2(39), 37-45 (2017, Tbilisi, in Georgian)

6. O. Lanchava, N. Ilias, G. Nozadze, S. Radu, R. Moraru, Z. Khokerashvili, N. Arudashvili, Proceedings of 8th International Symposium "Occupational Health and Safety" SESAM 2017, 342-352 (2017)

7. O. Lanchava, G. Nozadze, Z. Khokerashvili, Proceedings of $9^{\text {th }}$ International Conference "Contemporary problems of architecture and construction", 390-392 (2017)

8. C. Di Perna, A. Carbonari, R. Ansuini, M. Casals, Tunnelling and Underground Space Technology 42, 25-39 (2014)

9. J. Wang, L. Zhao, D. Zhu, H.O. Gao, Y. Xie, H. Li, X. Xu, H. Wang, Transportation Research Part D47, 77-88 (2016)

10. L. Mendes, M.I. Gini, G. Biskos, I. Colbeck, K. Eleftheriadis, Environmental Pollution 239, 8294 (2018)

11. T. Moreno, V. Martins, X. Querol, T. Jones, K. BéruBé, M.C. Minguillón, F. Amato, M. Capdevila, E. de Miguel, S. Centelles, W. Gibbons, Science of the Total Environment 505, 367-375 (2015)

12. Y. Zhang, X. Li, Journal of Wind Engineering \& Industrial Aerodynamics 175, 384-390 (2018)

13. L. Yang, Y, Zhang, J. Xia, Sustainable Cities and Society 37, 275-287 (2018)

14. Z. Yang, X. Su, F. Ma, L. Yu, H. Wang, J. Wind Eng. Ind. Aerodyn. 147, 120-131 (2015) 